\title{
Thearapeutic Management of Neonatal Calf Pneumonia in HF calf - A Case Report
}

\author{
Veena M.P.* and Sumathi B.R. \\ Veterinary Hospital, \\ Department of Animal Husbandry and Veterinary Services \\ Malavally, Mandya District - 571430 \\ * Corresponding author email: mp.veenarani@gmail.com
}

\section{Introduction}

Pneumonia is a very common problem affecting calves leads to greater economic losses and death. It is second major hazard (followed by calf enteritis) to calf health and may account for $50 \%$ of calf mortality. The causes of calf pneumonia are multifactorial involving interaction of infectious agents, the environmental factors and managemental practices. The infectious agent includes variety of viruses, bacteria and mycoplasma (Radostitis et al., 2003). Pasturella species which mainly are commensale organism present in the upper respiratory tracts causes acute bronchopneumonia (Radostitis et al., 2003). Two types of pneumonia are seen very frequently which are proliferative and exudative in calves (Trigo et al., 1982). The present report place on record a typical case of neonatal calf pneumonia in Holstein-Frisian calf and its successful thearapeutic management.

\section{History and Clinical Observation}

A 3 weeks old HF calf was presented to veterinary hospital, Malavally, Mandya with the history of being dull, depressed, lethargic and anorectic. The calf was showing respiratory distress with bilateral nasal discharge, frequent coughing and dyspnoea. The nasal discharge was copious and mucopurulent. Clinical examination revealed increased body temperature $(103-104 \mathrm{oF})$, increased heart rate (115-120/minutes) and increased respiration rate (35-38/mimutes) with shallow respiration. Lung auscultation revealed adventitious sounds mainly the crackles (moist rales). The above clinical signs were in close aggrements with the findings of Verma et al. (1995), Sen and Albay (2003) and Wadhwa et al. (2006). The Symptoms are due to inflammation of respiratory tracts along with presence of secretion and exudates in air ways (Radostitis et al. (2003).
Diagnosis: Diagnosis was done on the basis of corelation of history, clinical observation and auscultation of lungs.

\section{Treatment and Discussion}

The calf was treated with Amoxicillin and Clavulanic acid combination @ 2.5mg/Kg body weight, IM, BID for 5 days, injection Anistamina (Chlorphenaramine maleate) @ 3ml SID for 5 days, Melonexa (Meloxicam) @ 4ml, SID for 5 days and injection Tribiveta ( B1, B6 \& B12) @ 3ml, IM SID for 5 days.

The calf was responded to the treatments after 2nd days on wards which was indicated by improvement in the respiration rates, decrease in sneezing and grunt, dyspnoea and nasal discharge. The complete recovery was seen after 5 days. The present recovery status was incoordination with Sen and Albay (2003) who reported $92 \%$ recovery rate with the use of Amoxicillin and Clavulanic acid combination. Similarly verma et al. (1995) reported 60\% recovery rate with Ampicillin and Wadhwa et al. (2006) observed $91 \%$ recovery rate with Enrofloxacin.

\section{References}

1. Radostitis, o.M., Blood, D.C. and Hinchcliff, K.W. (2003) Veterinary Medicine 9th Edn, W.B. Saunders company Ltd. London.

2. Sen, S. and Albay, M.K. (2003). Etiology of respiratory tract infection in calves and evaluation of amoxicillin and clavulanic acids. Indian Vet. J. 80:519-21.

3. Trigo TE, Trigo TF, Hernandez LG, Ramirez CC and Berruecos VM. (1982). Pathology and Bacteriology of calf pneumonia. Veterinaria Mexico 13:131-40.

4. Verma, B.K., Thakur, D.K. and Sinha, A.K. (1995). Studies on respiratory infection in neonatal calves. Indian Vet. $J$. 15:77-78

5. Wadhwa, D., Wadhwa, D.R., Kumari Meena and B.S. Katoch. (2006). Thearapeutic efficacy of Enrofloxacin (Quinintas) in neonatal calf pneumonia. Intas polivet 7:54-55. 